\title{
Dietary fat and cardiovascular disease: possible modes of action of linoleic acid
}

\author{
By A. J. Vergroesen, Department of Biology, Unilever Research, Vlaardingen, \\ The Netherlands
}

\section{Introduction}

Most investigators studying atherosclerosis will accept that there are sufficiently convincing epidemiological findings to indicate a relation between dietary composition, especially dietary fat, and cardiovascular disease in different population groups. Based on this evidence many experiments with animals have been performed, some of which meet the necessary requirements for comparisons with the conditions in humans (Malmros \& Wigand, 1959; Thomasson, 1965; Malmros, 1969). In these experiments, the degree of atherosclerosis was dependent on the type of dietary fat, and was always well correlated with increased blood lipid concentrations during the experimental period, and the histological picture showed a remarkable similarity with that of human atherosclerosis (Constantinides, I965; Pollak, 1965). On the basis of these facts it was concluded that the type of dietary fat also influences human atherosclerosis. Clinical trials generally confirmed the beneficial effect on ischaemic heart disease of an increased intake of linoleic acid and a decreased intake of saturated fatty acids and cholesterol (Turpeinen, r 968 ; Dayton, Pearce, Hashimoto, Dixon \& Tomiyasu, 1969; Leren, I970).

As might be expected, a favourable clinical effect was always accompanied by a significant decrease in blood lipid concentrations. In most trials only cholesterol concentrations were studied, but recently Carlson \& Böttiger (1972) demonstrated that triglyceride concentrations might be even more important. Although there is no conclusive proof that the blood lipid lowering effect of a diet is causally related to the decrease of ischaemic heart disease complicating the already existing atherosclerosis, the available circumstantial evidence for this is quite strong.

\section{Effects of dietary fat on blood lipid concentrations}

Accepting the favourable effect of lowering blood lipid concentrations, the studies on the quantitative and qualitative effects of dietary fatty acids on serum lipids in man are of interest (among others, Hegsted, McGandy, Myers \& Stare, 1965; Keys, Anderson \& Grande, 1965a,b; Thomasson, Boer \& Iongh, 1967; Vergroesen \& Boer, 1971). However, considerable confusion still exists whether a reduction of saturated fatty acid or an increase of polyunsaturated fatty acid concentration in the diet is the more effective approach in lowering human blood lipid concentrations. 
When the blood lipid-increasing effects of the various saturated fatty acids were examined, it was found that lauric and myristic acids each have a stronger effect than palmitic acid; stearic acid and fatty acids with shorter chain lengths than lauric acid probably act similarly to oleic acid (I8:I $\Delta$ 9-cis). Furthermore, we recently observed that elaidic acid (I8:1 $\triangle$ 9-trans) in the presence of cholesterol has a definite serum cholesterol increasing effect compared with 18:1 $\Delta$ 9-cis (Fig. 1). In fact, I 8:1 $\Delta$-trans is only slightly less active than a mixture of lauric acid and myristic acid consumed in equal amounts.

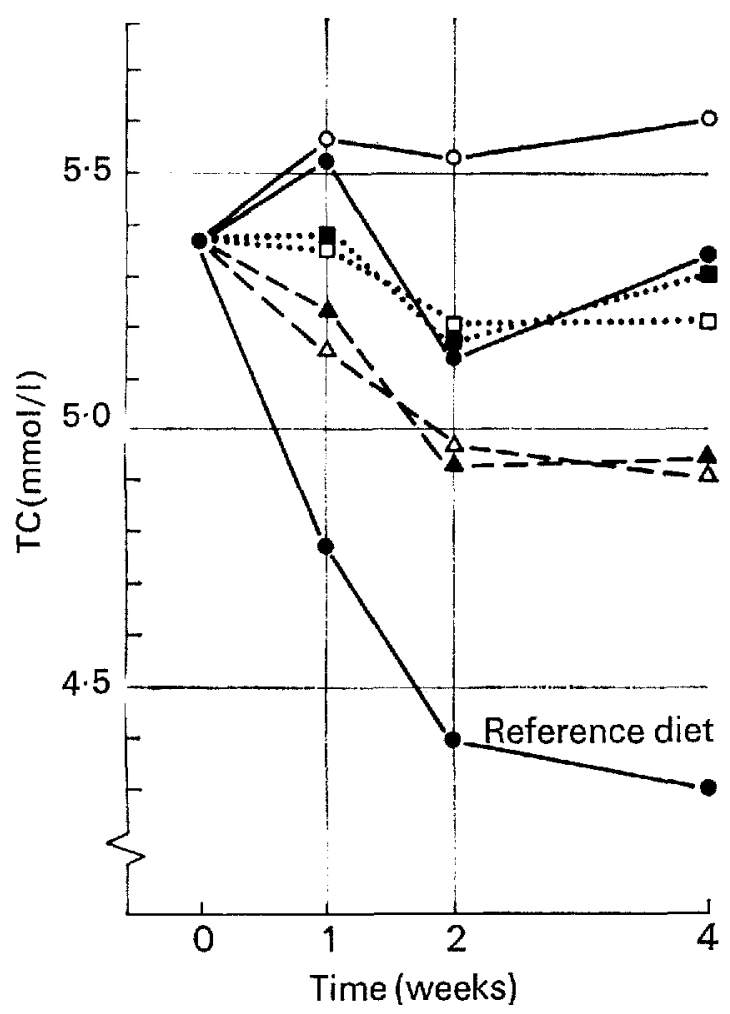

Fig. I. Influence of a liquid formula diet (LFD), with $40 \%$ dietary energy provided by fat, given during 4 weeks on fasting total serum cholesterol concentrations (TC) in male and female volunteers. The percentage composition of the six experimental fatty acid mixtures (prepared by mixing coconut oil, and hardened and unhardened olive oil with safflower-seed oil) was as follows:

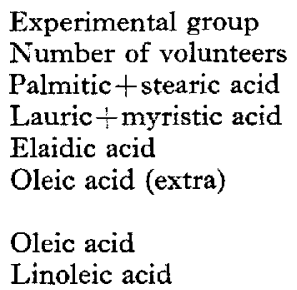

Experimental group

Number of volunteers

Lauric - myristic acid

Elaidic acid

Oleic acid

Linoleic acid

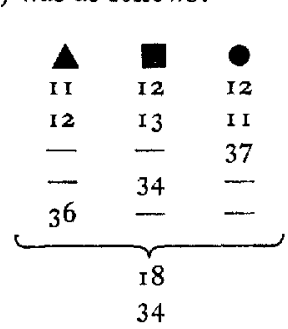

Dried egg yolk was added to these mixtures to obtain a LFD containing I I $5 \mathrm{mg}$ cholesterol/1000 kcal $(4 \cdot 184 \mathrm{MJ})$ (average daily LFD consumption about $1900 \mathrm{kcal}(7 \cdot 949 \mathrm{MJ})$. As reference diet a cholesterolfree LFD, with $40 \%$ dietary energy provided from the fat in safflower-seed oil, was used. For further technical details, see Vergroesen \& Boer (I 97I). 
In a previous experiment (Vergroesen, 1973) $35 \%$ elaidic acid in a liquid formula diet (LFD) providing $40 \%$ dietary energy (DE) from fat (including one egg yolk per d) was found to increase serum cholesterol even more than palmitic acid at the same concentration. Interestingly, but still unexplainable, i8: $\Delta 4$ 9-trans in the absence of dietary cholesterol had the same effect on blood lipids as I8:1 $\Delta$ 9-cis. These results explain the apparent discrepancies in the results of Anderson, Grande \& Keys (1961), who described significant rises in blood lipid concentrations caused by elaidic acid present in a 'typical' American, cholesterol-rich diet, and those of Iongh, Beerthuis, Hartog, Dalderup \& Spek (1965) and of McOsker, Mattson, Sweringen \& Kligman (1962), who concluded that elaidic acid in their experiments, in which diets very low in cholesterol and cholesterol-free diets were used, respectively had no, or only a very slight, influence on serum cholesterol concentrations.

These facts in themselves indicate that 'Keys' (Keys, Anderson \& Grande, I959) equation' $\Delta$ Chol. $=2.68 \Delta \mathrm{S}-\mathrm{I}_{2} 3 \Delta \mathrm{P}$ (Anderson et al. 1961) (Chol.=serum total cholesterol; $\Delta$ Chol. is measured in $\mathrm{mg}$ per roo $\mathrm{ml}$ of serum), in which $\Delta \mathrm{S}$ and $\Delta \mathrm{P}$ are the differences between two diets in saturated and polyunsaturated fatty acid glycerides, measured as percentages of total dietary energy, is not generally applicable for the prediction of the efficacy ( $\Delta \mathrm{Chol}$.) of a dietary change on serum cholesterol concentration. Again with regard to variations in polyunsaturated fatty acids $(\Delta \mathrm{P})$, no certain relation with blood lipid concentrations appears to be present. Fig. I also shows that increasing the linoleic acid content of the dietary fat from ro to $34 \%$ (at the expense of oleic acid) seems to influence the effects of $37 \%$ of a lauric and myristic fatty acid mixture on serum cholesterol concentration confirming the previous results of Thomasson et al. (1967) obtained with a cholesterol-free LFD experiment - but not those of $34 \%$ elaidic acid or $36 \%$ oleic acid. Furthermore, according to Ahrens, Insull, Hirsch, Stoffel, Peterson, Farquhar, Miller \& Thomasson (1959), the hypocholesterolaemic activity of polyunsaturated oils is in fact the reflection of their total degree of unsaturation; thus this activity is independent of relative content of these oils of essential fatty acids (actually i $8: 2 \omega 6$ ). Peifer ( 1967 ) reviewed the available results on hypocholesterolaemic effects of marine oils, which are generally characterized by very low $18: 2 \omega 6$ and relatively high 20:5 $\omega_{3}+22: 6 \omega_{3}$ concentrations. He concluded that, in man, rat, chicken and mouse, linolenic acid ( $\left.18: 3 \omega_{3}\right)$ and its homologues, as well as marine oils such as menhaden and cod-liver oil, have a greater hypocholesterolaemic effect than, for instance, maize oil or safflower-seed oil. Although the available results from studies with human subjects who were encouraged to eat more fish, or combinations of fish and fish oils, do not permit of any final conclusions, an increased intake of fish might induce lower blood lipid concentrations.

As to the quantitative effects of linoleic acid on blood cholesterol concentrations, it should be noted that extremely high amounts of linoleic acid will not improve on the $20-25 \%$ reduction in blood cholesterol concentrations already obtainable with, for instance, a $35 \%$ DE provided from the fat of safflower-seed oil (Vergroesen \& Boer, 1971). Furthermore, the results of our experiments with cholesterol-free 
LFD providing $50 \%$ DE from fat, suggested that $25 \%$ of, saturated fatty acids (12:0, $14: 0,16: 0$ or $18: 0$ ) in the presence of more than $70 \%$ linoleic acid no longer clearly influenced total blood cholesterol (TC) and lipoid phosphorus (LP) concentrations. The question then arose whether this might also be true for a normal Dutch diet, which is characterized by fat providing $40-45 \%$ DE and a daily intake of 200-500 mg cholesterol. Thanks to the co-operation of about roo adolescents ( $12-18$ years old, $80 \%$ of whom were boys) treated for an asthmatic condition in an open institute (Medical Director, Dr J. E. C. Schook), we were able to study the effects of drastic changes in the fatty acid composition of the 'visible' fat part of their diet, but without varying total fat, protein, carbohydrate, and cholesterol intake. When the normal institutional diet was changed to one with butter as the main visible fat, a moderate but significant $(P<0.0 \mathrm{I})$ rise of both TC and LP concentrations occurred. The substitution of a margarine with $50-55 \%$ linoleic acid and about $25 \%$ saturated fatty acids, sunflower-seed oil for deep frying, and a filled milk $(3.5 \%$ safflower-seed oil in skimmed milk) for butter, lard, and normal milk $(3.5 \%$ butterfat) resulted in a highly significant decrease in TC $(\Delta$ Chol. $=20-25 \%)$ and LP $(\triangle \mathrm{LP}=$ about $15 \%)$ concentrations. In this study there was a normal intake of cholesterol (eggs, meat, liver, and cheese were not restricted) and there was a high percentage of saturated fatty acids in the 'invisible fat' part of the diet. Nevertheless, the changes in the averge TC and LP concentrations were about equal to those we observed in rigidly controlled cholesterol-free LFD experiments, in which safflower-seed oil $(75 \%$ linoleic acid and less than 10\% saturated fatty acids--mainly palmitic acid) was the only source of fat. During the high linoleic acid periods the adolescents consumed $20-25 \%$ De from fat from linoleic acid, which apparently is sufficient to compensate fully for the blood lipid increasing effects of saturated fatty acids (about $10 \%$ DE from fat) and cholesterol. This is in complete agreement with the conclusions which Brown (197I) draws from her own, Keys' and Hegsted's dietary studies. I quote: 'To obtain an adequate reduction in serum cholesterol, the polyunsaturated fatty acid requirement increases as the dietary cholesterol rises in the diet. For a reduction of 18 to 22 per cent in serum cholesterol a diet with $200 \mathrm{mg}$ cholesterol requires i 5 per cent of calories as polyunsaturated fatty acids, and one with $55^{\circ} \mathrm{mg}$ requires 23 per cent'.

Furthermore, no differences in effect were observed between DE from fat of 17 and $23 \%$ from linoleic acid if the DE from fat from saturated fatty acid was Iп \% or less. McGandy, Hall, Ford \& Stare (1972) recently published the results of a pilot study on dietary regulation of blood cholesterol in adolescent males, which to some extent is comparable to ours, but linoleic acid intake was increased only by $10 \%$ of DE from fat to a total of $13 \%$. Although the mean fall in TC concentration (from 189 to $172 \mathrm{mg} / 100 \mathrm{ml}$ ) was highly significant $(P<0.00 \mathrm{r})$, it was much less than the decrease in TC concentration observed in our study (from 192 to $149 \mathrm{mg}$ ) I00 $\mathrm{ml}$ ). Apparently the maximum effect of linoleic acid will manifest itself first at concentrations higher than $\mathrm{I} 3 \%$ DE from fat; according to Brown (1971), however, even $17 \%$ is sufficient. 


\section{Possible modes of action of linoleic acid}

The preceding findings mainly concern the regulation of blood lipids in man. The favourable influence of high-linoleic acid low-saturated fat diets on the prevention or inhibition of atherosclerotic disease is commonly explained by its blood cholesterol lowering effect.

According to the 'filtration theory', lipoproteins diffusing from the blood into the arterial wall can be trapped in the intima to a degree depending on concentration of blood lipids, arterial blood pressure, and permeability of the vessel wall. Although the lowering effect on blood lipids of linoleic acid is still largely unexplained, part of its efficacy in lowering plasma cholesterol has been ascribed to an increased removal of cholesterol as bile acids (Holman, I970). E. H. Ahrens Jr and some other investigators (see, for example Grundy \& Ahrens, 1970) conclude from their studies that the decrease in plasma cholesterol concentration should be explained by an increase in cholesterol content of other tissues and, on these grounds, doubt the clinical value of dietary linoleic acid in the treatment of hyperlipidaemias. However, the results of their short-term studies are in complete disagreement with those of long-term animal and clinical studies in which dietary-induced lower plasma cholesterol concentrations are accompanied by, for instance, less cholesterol ester deposits in the arterial intima and the gradual disappearance of cholesterolrich lesions in the skin and around the retinal arteries in the eye.

Intra-arterial thrombosis plays a role in atherosclerosis, not only because it is partly responsible for the mortality due to atherosclerosis (Owren, 1964), but also because it might be a primary factor in the aetiology of the disease (Mustard, Downie, Murphy \& Rowsell, 196r). According to Hoak, Spector, Fry \& Warner (1970), in vitro exposure of blood platelets to high concentrations of fatty acids will increase the responsiveness to $\mathrm{ADP}$, collagen and other agents which influence platelet stickiness in vivo, leading to the formation of thrombi. However, albuminbound linoleic acid had much less effect on platelet aggregation than palmitic acid.

Under certain conditions, for instance high catecholamine concentrations caused by stress, release of free fatty acids from adipose tissue will increase very significantly; so the type of fatty acid released, as determined by dietary history, might decide whether stress will or will not result in an increased susceptibility to thrombosis. The in vitro experiments by Hoak et al. ( 1970 ) have been supplemented by the recently published in vivo studies of Hornstra (I97I). A polyethylene cannula was inserted in the aorta of rats and, after a variable time (the obturation time, OT), platelet thrombi, which are induced at the tips of the cannula, block the aorta completely. When the rats are given diets containing increasing amounts of sunflower-seed oil (containing $63 \%$ linoleic acid) a positive, rectilinear relationship between OT and linoleic acid dose was found. This effect can possibly be explained by a changed fatty acid composition of the cellular membranes of endothelium and platelets which might decrease, in an unknown way, the thrombotic properties of these tissues.

However, another explanation might be given by accepting the possibility of an increased biosynthesis of prostaglandin $(\mathrm{PG}) \mathrm{E}_{1}\left(\mathrm{PGE}_{1}\right)$, a highly potent inhibitor of platelet adhesion and aggregation. In many organs $\mathrm{PGE}_{1}$ is synthesized from 


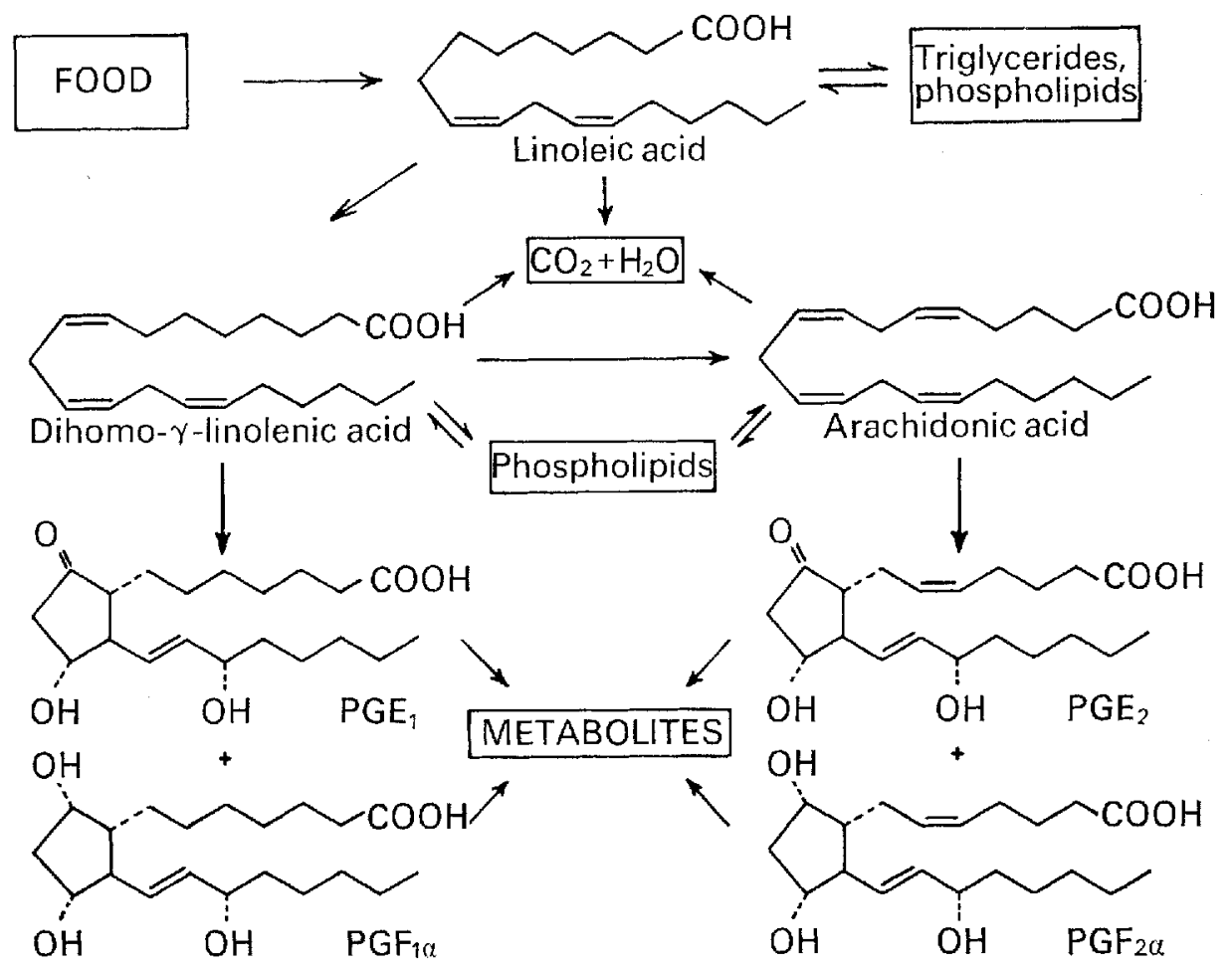

Fig. 2. Metabolic pathways of dietary linoleic acid.

dihomo- $\gamma$-linolenic acid, an intermediate formed during the conversion of linoleic acid into arachidonic acid (Fig. 2). Thomasson (1969) postulated that by increasing dietary linoleic acid concentrations PG synthesis might be stimulated and that at least part of the favourable effects of linoleic acid in respect to atherosclerosis can be explained in this way. Thomasson's hypothesis is based on the following facts. Apart from the inhibiting effect of $\mathrm{PGE}_{1}$ on platelet aggregation and adhesion, $\mathrm{PGE}_{1}$ and also $\mathrm{PGE}_{2}$ have a lowering effect on blood pressure, antagonize the hypertensive properties of adrenaline and angiotensin, are potent inhibitors of catecholamine-induced free fatty acid release from adipose tissue, increase natriuresis, especially after this being inhibited by vasopressin, and finally decrease the influence on myocardial tissue of both sympathetic and parasympathetic nerve stimulation (Bergström, Carlson \& Weeks, 1968; Vergroesen, Gans, Gottenbos \& Hoor, 1971). These findings indicate that the $\mathrm{PG}$ might have an important physiological function by regulating the cyclic AMP synthesis rate due to different hormonal impulses. As hypertension increases, thrombotic tendency of platelets, high concentrations of plasma lipids, and increased sympathetic or parasympathetic tone are risk factors in atherosclerotic heart disease; the effects of the PG that have been mentioned suggest a preventive or curative role of linoleic acid through an increased PG synthesis. Several investigations have already demonstrated that increasing the amount of precursor fatty acids in the perfusion medium of isolated organs (heart 
and umbilical cord) or giving linoleic acid to animals that are deficient in essential fatty acids results in an increased $\mathrm{PG}$ synthesis in rabbit kidney, rat skin and adipose tissue (Dorp, r97 $r$ ).

Further research will be needed before a definite conclusion can be drawn with respect to the question which of these possible modes of action of linoleic acid is the most important. Finally, the whole problem is complicated even more by the apparently existing great inter-individual differences in requirement for linoleic acid which can only incompletely be explained by the interactions already recognized between linoleic acid and other dietary factors.

\section{REFERENCES}

Ahrens, E. H. Jr, Insull, W. Jr, Hirsch, J., Stoffel, W., Peterson, M. L., Farquhar, J. W., Miller, T \& Thomasson, H, J. (I959). Lancet i, II5.

Anderson, J. T., Grande, F. \& Keys, A. (196r). F. Nutr. 75, 388.

Bergström, S., Carlson, L. A. \& Weeks, J. R. (1968). Pharmac. Rev. 20, I.

Brown, H. B. (1971). F. Am. diet. Ass. 58, 1303.

Carlson, L. A. \& Böttiger, L. E. (1972). Lancet i, 865.

Constantinides, P. (I965). In Comparative Atherosclerosis p. 276 [J. C. Roberts Jr and R. Straus, editors]. New York: Hoeber Medical Division, Harper \& Row.

Dayton, S., Pearce, M. L., Hashimoto, S., Dixon, W. J. \& Tomiyasu, U. (1969). Circulation 40, Suppl. no. 2.

Dorp, D. A. van (1971). Ann. N.Y. Acad. Sci. 180, r8r.

Grundy, S. H. \& Ahrens, E. H. Jr. (1970). F. clin. Invest. 49, II35.

Hegsted, D. M., McGandy, R. B., Myers, M. L. \& Stare, F. J., (I965). Am. F. clin. Nutr. 17, 28 I.

Hoak, J. C., Spector, A. A., Fry, G. L. \& Warner, E. D. (1970). Nature, Lond. 228, 1330.

Holman, R. T. (editor). (1970). In Progress of the Chemistry of Fats and Other Lipids Vol. 9, Polyunsaturated Acids, Part 5, p. 607. Oxford: Pergamon Press.

Hornstra, G. (1971). Nutr. Metab. 13, I40.

Iongh, H. de, Beerthuis, R. K., Hartog, C. den, Dalderup, L. M. \& Spek, P. A. F. van der (1965). Nutritio Dieta 7, 137.

Keys, A., Anderson, J. T. \& Grande, F. (1959). Circulation 19, 201.

Keys, A., Anderson, J. T. \& Grande, F. (1965a). Metabolism 14, 759.

Keys, A., Anderson, J. T. \& Grande, F. (1965b). Metabolism 14, 776.

Leren, P. (1970). Circulation 42, 935.

McGandy, R. B., Hall, B., Ford, C. \& Stare, F. J. (1972). Am. f. clin. Nutr. 25, 6r.

McOsker, D. E., Mattson, F. H., Sweringen, H. B. \& Kligman, A. M. (Ig6z). $\%$. Am. med. Ass. I80, 380 .

Maimros, H. (r969). Lancet ii, 479 .

Malmros, H. \& Wigand, G. (1959). Lancet ii, 749.

Mustard, J. F., Downie, H. G., Murphy, E. A. \& Rowsell, H. C. (1961). In Blood Platelets p. 19I [S. A. Johnson, R. W. Monto, J. W. Rebuck and R. C. Horn Jr, editors]. Boston, Mass.: Little, Brown \& Co.

Owren, P. A. (1964). Nutritio Dieta 6, i 56 .

Peifer, J. J. (1967). In Fish Oils p. 322 [M. E. Stansby, editor]. Westport, Connecticut:, The Avi Publishing Company.

Pollak, O. J. (1965). In Comparative Atherosclerosis p. 29I [J. C. Roberts, Jr and R. Straus, editors]. New York: Hoeber Medical Division, Harper \& Row.

Thomasson, H. J. (1965). In Fette in der Medizin, Part 5, p. I9. Lockham: Pallas Verlag.

'Thomasson, H. J. (1969). Nutritio Dieta Ir, 228.

Thomasson, H. J., Boer, J. de \& Iongh, H. de (1967). Pathologia Microbiol. 30, 629.

Turpeinen, O. (1968). F. Am. diet. Ass. 52, 209.

Vergroesen, A. J. (editor) (1973). The Role of Fats in Human Diet London \& New York: Academic Press. (In the Press.)

Vergroesen, A. J. \& Boer, J. de (1971). In Wissenschaftliche Veröffentlichungen der Deutschen Gesellschaft für Ernährung Band 22, Polyenfettsäuren p. 76. Darmstadt: Dietrich Steinkopff Verlag.

Vergroesen, A. J., Gans, P., Gottenbos, J. J. \& Hoor, F, ten (1971). Klin, Wschr. 49, 889.

\section{Printed in Great Britain}

